\title{
Análise da eficiência na geração de retorno aos acionistas das empresas do setor da construção civil com ações negociadas na BM\&FBOVESPA nos anos de 2009 e 2010 por meio da análise envoltória de dados
}

Analysis of efficiency in the generation of shareholder return of companies in the construction sector with shares traded at BM\&FBOVESPA in the years of 2009 and 2010 through data envolopment analysis

\section{Idalberto José das Neves Júnior}

Mestre em Gestão do Conhecimento e Tecnologia da Informação pela Universidade Católica de Brasília (UCB)

Professor dos Cursos de Ciências Contábeis da Universidade Católica de Brasília (UCB)

Gerente de Divisão da Diretoria de Controladoria do Banco do Brasil S.A.

Endereço: Campus I - QS 07 Lote 01 EPCT, Águas Claras

CEP: 71966-700 - Taguatinga/DF - Brasil

E-mail: jneves@ucb.br

Telefone: (61) 3356-9000

\section{Simone Alves Moreira}

Especialista em Auditoria e Perícia

Professora dos Cursos de Ciências Contábeis da Universidade Católica de Brasília (UCB)

Endereço: Campus I - QS 07 Lote 01 EPCT, Águas Claras

CEP: 71966-700 - Taguatinga/DF - Brasil

E-mail: simonea@ucb.br

Telefone: (61) 3356-9000

Erivaldo dos Santos Vasconcelos

Bacharel em Ciências Contábeis pela Universidade Católica de Brasília (UCB)

Endereço: Campus I - QS 07 Lote 01 EPCT, Águas Claras

CEP: 71966-700 - Taguatinga/DF - Barsil

E-mail: contadoreri@gmail.com

Telefone: (61) 3356-9000

\section{Juliano Lima Brito}

Bacharel em Ciências Contábeis pela Universidade Católica de Brasília (UCB)

Endereço: Campus I - QS 07 Lote $01 \mathrm{EPCT}$, Águas Claras

CEP: 71966-700 - Taguatinga/DF - Brasil

E-mail: julianolbrito@ hotmail.com

Telefone: (61) 3356-9000

Artigo recebido em 20/12/2011. Revisado por pares em 01/06/2012. Reformulado em 12/10/2012. Recomendado para publicação em 17/10/2012 por Sandra Rolim Ensslin (Editora Científica). Publicado em 14/12/2012. 


\title{
Resumo
}

Este trabalho analisa a eficiência das empresas do setor da construção civil em gerar retorno aos acionistas nos anos de 2009 e 2010, por meio da Análise Envoltória de Dados, considerando o Patrimônio Líquido como input, e lucro líquido, dividendos e variação no preço da ação, como outputs. Os dados foram obtidos por meio da coleta no software Economática ${ }^{\circledR}$ e na base de dados disponível no site da BM\&FBovespa, e analisados no software SIAD. Como principal resultado, verificou-se que a Helbor Empreendimentos S.A. foi a mais eficiente em gerar retorno ao acionista dentro do grupo analisado, enquanto a Viver Incorporadora e Construtora S.A. foi a menos eficiente.

Palavras-chave: Eficiência. Retorno ao acionista. Construção civil. Análise envoltória de dados.

\begin{abstract}
This work analyzes the efficiency of the companies in the sector of civil construction in generating return to the shareholders in the years of 2009 and 2010, by means of Data Envelopment Analysis, considering Equity as input, and net profits, shares and variation in the share price, as outputs. The data were obtained by collecting in Economática ® software and database available on BM\&FBovespa website, and analyzed in SIAD software. As main result, it was verified that Helbor Empreendimentos S.A. was the most efficient in generating return to the shareholder within the analyzed group, while Viver Incorporadora e Construtora S.A. was the least efficient.
\end{abstract}

Keywords: Efficiency. Return to the shareholder. Civil construction. Data envelopment analysis.

\section{Introdução}

O setor da construção civil, a partir de 2004, experimentou significativo crescimento, fazendo com que muitas empresas optassem pela abertura de capital como um dos meios para financiar a expansão de suas capacidades produtivas.

Um dos indicadores desse crescimento é o aumento, no decorrer dos anos, da contribuição do setor para a formação do Produto Interno Bruto (PIB), representada pelo Valor Adicionado Bruto (VAB), o qual, de acordo com a Câmara Brasileira da Indústria da Construção (CBIC), foi de 4,7 \% em 2004, 7,9\% em 2008, 8,3\% em 2009 e de 11,6\% em 2010.

Quanto à abertura de capital das empresas do setor, em pesquisa feita por Cardia et al. (2008), que procuraram mostrar em quais Ativos foram aplicados os recursos captados pelas empresas que abriram capital na Bolsa no período de 2004 a 2006, os autores afirmam que:

Destaque especial deve ser dado às empresas do setor imobiliário, que investiram pesadamente na aquisição de terrenos para lançamento de novos 
empreendimentos, [...]. As empresas do setor de construção civil representam a maioria das empresas que abriram capital no período de janeiro de 2004 a abril de 2006 e merecem destaque também por comporem a maioria das empresas listadas no Novo Mercado (CARDIA et al., 2008, p. 12).

Quando uma empresa abre capital, é necessário que ela seja eficiente em utilizar os recursos captados dos acionistas, gerando retorno para estes, pois, caso não o faça, eles certamente retirarão seu capital da empresa ineficiente, reinvestindo-o em outras que lhe proporcionem melhores retornos (ASSAF NETO, 2010).

Considerando esse crescimento do setor, a maioria das empresas tendo optado pelo financiamento da expansão de suas capacidades produtivas por meio da abertura de capital na Bolsa e a necessidade de geração de retorno aos acionistas, surge a questão de pesquisa que este estudo busca responder: Qual é a fronteira de eficiência na geração de retorno aos acionistas das empresas do setor da construção civil com ações negociadas na BM\&FBovespa de 2009 e 2010 ?

Assim, o objetivo principal deste estudo é evidenciar a fronteira de eficiência na geração de retorno aos acionistas das empresas do setor da Construção Civil com ações negociadas na BM\&FBovespa de 2009 e 2010. E, como objetivos específicos, pretende-se (i) construir o ranking de eficiência relativa das empresas; (ii) identificar as empresas eficientes e as ineficientes; e, (iii) evidenciar metas de melhoria para as empresas ineficientes alcançarem a eficiência.

Ao evidenciar a eficiência ou não das empresas, este estudo traz uma contribuição tanto aos acionistas correntes ou potenciais, quanto às próprias empresas. Aos acionistas porque os resultados podem lhes servir como auxílio na tomada de decisão sobre investir/continuar investindo ou não em determinada empresa do setor, dado o histórico de eficiência de cada uma; e às empresas, sobretudo às ineficientes, porque ao conhecer o seu grau de eficiência em relação ao conjunto analisado, bem como as metas de melhoria, podem utilizar tais informações como indicadores para realinhamento de estratégias de investimentos e aplicação dos capitais dos acionistas, de forma a maximizar o retorno.

Segundo Vergara (2000), esta pesquisa classifica-se, quanto à sua finalidade, em descritiva e metodológica, e quanto aos meios de investigação, como pesquisa bibliográfica e documental. De acordo com Martins e Theóphilo (2009), pode ainda ser classificada como positivista.

Para a realização da pesquisa, foi feita coleta dos dados por meio do software Economática $^{\circledR}$ e na base de dados disponível no site da BM\&FBovespa (www.bmfbovespa.com.br), tratamento dos dados em planilhas no Microsoft Excel $^{\circledR}$ para, em seguida, proceder-se à análise com a aplicação do modelo Análise Envoltória de Dados por meio do software SIAD.

\section{Revisão da literatura}

\subsection{Eficiência e retorno ao acionista}

Ross (2002) afirma que, antes de poder investir num ativo, uma empresa precisa obter financiamento, ou seja, deve levantar o dinheiro necessário para pagar o investimento. Para 
obtenção desse dinheiro, a empresa pode lançar mão de duas fontes distintas de financiamento: recursos de terceiros e recursos próprios.

Uma alternativa para financiamento por meio de recursos próprios é a abertura de capital e o lançamento de ações nas Bolsas de Valores. Na literatura, esse processo de abertura de capital é mais comumente denominado como Initial Public Offering, ou simplesmente $I P O$, que significa oferta pública inicial.

No Brasil, a principal Bolsa de Valores que faz intermediação para operações no mercado de capitais é a Bolsa de Valores, Mercadorias e Futuros de São Paulo (BM\&FBovespa). De acordo com a BM\&FBovepsa (2011), "as ações são títulos nominativos negociáveis que representam, para quem as possui, uma fração do capital social de uma empresa". O possuidor da ação é chamado de acionista e é proprietário da empresa proporcionalmente à quantidade de ações que possui.

De acordo com Assaf Neto (2008), os acionistas investem seu capital na empresa com a expectativa de obter retorno sobre o investimento, o que implica, para a empresa, a obrigação de ser eficiente em utilizar os recursos investidos, maximizando o retorno para os acionistas.

Nesse sentido, Gitman (2004) declara que o objetivo da empresa e de todos os administradores e empregados é o de maximizar a riqueza dos proprietários. Iudícibus (2010, p. 111) faz uma afirmação semelhante: "a principal tarefa da administração financeira é a de maximizar o valor de mercado para o possuidor das ações e estabelecer um fluxo de dividendos compensador".

Das afirmações de Gitman (2004) e Iudícibus (2010) depreende-se que os acionistas subestabelecem aos administradores das empresas o papel de minimizar o uso de recursos e maximizar os resultados na forma de lucros e dividendos.

Corroborando com essas declarações, Silva (2005) ratifica o entendimento de que os acionistas delegam o gerenciamento dos negócios a administradores profissionais, contudo evidencia a necessidade de avaliar a eficiência da administração na condução desses negócios, em face das expectativas de lucro, de segurança e até mesmo de continuidade e de imagem da organização.

Sobre a égide do termo eficiência, tem-se o seu significado no campo econômico, em sentido amplo, que diz respeito à combinação apropriada dos fatores de produção, a exemplo de recursos naturais, mão de obra, capital e administração, e se baseia na teoria criada pelo economista Vilfredo Pareto, a qual consiste na ideia de que o ponto ótimo de eficiência só pode ser alcançado quando não é possível aumentar algum componente do vetor de utilidades sem que se reduza qualquer dos outros componentes (PARETO, 1984).

Em sentido mais restrito, "eficiência" diz respeito à utilização eficaz dos recursos da empresa na realização de suas atividades e na geração de lucros.

\begin{abstract}
A definição de eficiência, da qual faz uso a teoria econômica, não diverge muito do conceito utilizado nas demais ciências sociais aplicadas. Tanto na Administração quanto na Economia, a eficiência refere-se à otimização de recursos e à ausência de desperdício. Assim, a eficiência se dá pela utilização máxima dos recursos existentes para satisfazer as necessidades e os desejos de indivíduos e organizações (FERREIRA; GONÇALVES; BRAGA 2007, p. $3)$.
\end{abstract}

De acordo com Kassai (2000), é importante afirmar que o conceito de eficiência se distingue de eficácia, pois esta se refere ao alcance de resultados, enquanto eficiência é a relação ótima entre resultados obtidos e recursos consumidos.

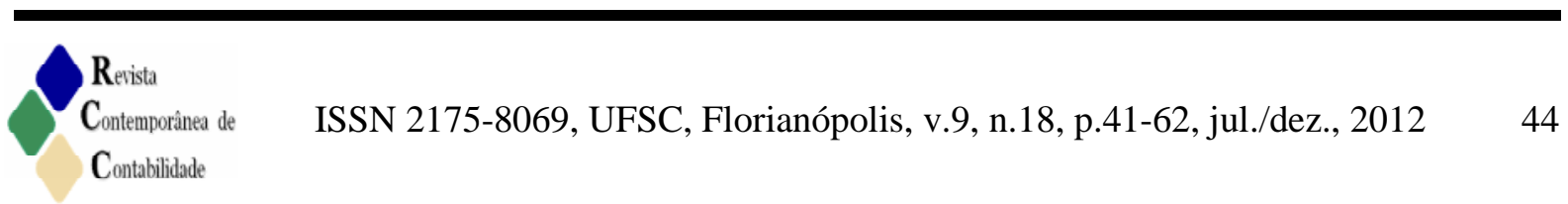


Hendriksen et al. (1999) definem a eficiência das empresas na utilização de capital dos proprietários porque

\begin{abstract}
Representa a capacidade relativa de obtenção do máximo resultado com um dado volume de recursos, um certo resultado com um mínimo de recursos, ou uma combinação ótima de recursos utilizados, permitindo a rentabilidade máxima para os proprietários (HENDRIKSEN et al., 1999, p. 202).
\end{abstract}

Adicionalmente, Assaf Neto (2010, p. 152) afirma que "o mercado competitivo atual deixa espaço somente para empresas eficientes, que se mostrem capazes de agregar valor em suas decisões".

Dessa forma, pode-se identificar que a abordagem dos temas eficiência e retorno para os acionistas, realizada pelos autores Ross (2002), Assaf Neto (2008), Gitman (2004), Silva (2005), Pareto (1984), Ferreira, Gonçalves e Braga (2007), Kassai (2000), Hendriksen et al. (1999) e Assaf Neto (2010), converge para o conceito de alocação de recursos para investimentos, visando ao retorno, aos ganhos de eficiência, à maximização de valor e ao uso eficaz desses recursos.

Nesse sentido, Matarazzo (2010) relata que um dos instrumentos utilizados para a avaliação da eficiência das empresas é a análise financeira de balanços que visa à extração de informações das demonstrações financeiras com o uso de processos de análise de balanços e da comparação com índices padrão do setor.

A análise das demonstrações financeiras por meio de índices visa basicamente à avaliação do desempenho da empresa, notadamente como forma de identificar os resultados retrospectivos e prospectivos das diversas decisões tomadas (ASSAF NETO, 2010).

Gitman (2004) afirma que os índices podem ser subdivididos em quatro grupos: liquidez, aspectos da atividade, endividamento e rentabilidade, sendo que os três primeiros medem, fundamentalmente, o risco, enquanto o quarto mede o retorno.

Os índices mais indicados para analisar o retorno aos acionistas, de acordo com Braga (1989), Martins e Assaf Neto (1996), Pereira da Silva (1997), Iudícibus (2000) e Matarazzo (2010), e confirmados por Krauter (2006) em pesquisa feita com 800 empresas industriais de médio e de grande porte de diversas áreas de atuação do estado de São Paulo, são os seguintes:

- ROI - Retorno sobre Investimento: é o quociente entre o lucro e o investimento.

- ROA - Retorno sobre o Ativo: é o quociente entre o lucro operacional e o ativo total. Mostra como os administradores estão utilizando os ativos.

- ROE - Retorno sobre Patrimônio Líquido: é o quociente entre o lucro líquido e o patrimônio líquido. Mede a rentabilidade sobre os recursos investidos pelos proprietários.

- RONA - Retorno sobre Ativos Líquidos: é a relação entre o lucro operacional líquido após imposto de renda (NOPAT) e o total de ativos.

- LPA - Lucro por Ação: é a relação entre o lucro líquido e o número de ações da empresa.

- Índice preço/lucro: é a razão entre o preço de mercado da ação e o lucro por ação.

Além da variável Lucro e Preço da ação, também se deve levar em consideração a variável Dividendos, pois, de acordo com Ross et al. (2002), o retorno ao acionista pode ser encontrado pela fórmula: Dividendos + ganho ou perda de capital. 
Para Cavalcante (2011), o retorno ao acionista pode ser medido pelo seu ganho de capital somado aos seus dividendos, comparados com seu valor inicial.

Ainda sobre a importância e o uso da variável Dividendos para a maximização de retorno, tem-se a abordagem de Hendriksen et al. (1999, p. 202), em que há a declaração de que "o funcionamento eficiente de uma empresa afeta tanto a série de dividendos correntes quanto o uso de capital aplicado para a geração de fluxos de dividendos futuros. Portanto, todos os investidores, mas particularmente os acionistas ordinários, preocupam-se com a eficiência da administração".

Sendo assim, a eficiência deve ser mensurada, evidenciada, avaliada e eventuais desvios devem ser objeto de análise e correção de rota.

Nesse sentido e visando ao apoio a esse processo, é possível depreender que os autores pesquisados destacam a importância do uso de indicadores de desempenho com foco no acompanhamento da eficiência e da eficácia dos investimentos vis-à-vis a maximização de retorno.

\subsection{Estudos similares sobre eficiência e retorno de ações}

Com o objetivo de identificar estudos similares sobre o tema deste trabalho, efetuou-se pesquisa em eventos e periódicos da área contábil e de finanças. Como resultados dessa pesquisa, optou-se por apresentar cinco trabalhos publicados no período de 2002 a 2012. A abordagem desses estudos é apresentada a seguir.

O estudo de Bueno (2002) que abordou os dividendos como estratégia de investimentos em ações propôs verificar a relação entre dividend yields e as taxas de retorno das ações, bem como a viabilidade de uma estratégia baseada em dividend yields históricos de "bater" o mercado, foram construídas, mensalmente, durante o período que vai do Plano Real, em julho de 1994 a dezembro de 1999, três diferentes carteiras (alto, baixo e zero).

Como resultados, foi possível verificar que a evidência empírica é incapaz de sugerir que as ações de altos dividend yields tendem a possuir maiores ou menores taxas de retorno do que as ações de baixo ou zero yield. Ademais, as evidências sugerem que não é possível demonstrar, usando o método empírico aplicado, uma clara associação entre dividend yield e taxas de retorno de ações.

No estudo de Santos e Coelho (2010), que objetivou analisar se a formação de carteiras de investimentos compostas por ativos internacionais pode proporcionar relações de risco e retorno mais vantajosas para o investidor, onde houve a aplicação da pesquisa em dois períodos: 1996 a 2000 e 2003 a 2007, e em quatro categorias: (1) índices de bolsas de países desenvolvidos (Reino Unido, EUA e Japão) e dos países que integram o bloco BRIC - Brasil, Rússia, Índia e China; (2) índices de bolsas de valores dos EUA e dos países que integram o BRIC; (3) índices de bolsas de valores dos países que integram o BRIC; (4) índices de bolsas de valores dos países desenvolvidos.

Os resultados da pesquisa sugerem que o investidor obteria melhores resultados, caso optasse por carteiras compostas pelos índices do mercado acionário dos Estados Unidos e dos países integrantes do BRIC.

Em outro estudo, desenvolvido por Lopes e Galdi (2010), onde o objetivo principal foi analisar a relevância das informações contábeis no retorno das ações no mercado brasileiro, de acordo com o modelo proposto e testado por Zhang e Chen (2007), foi possível evidenciar que os resultados obtidos indicam que o modelo é válido também para o mercado brasileiro,

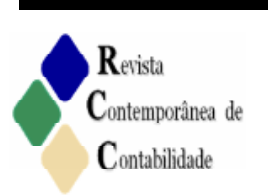


mesmo apresentando resultados com menor significância estatística que os encontrados pelos autores que desenvolveram a teoria.

Para Roth, Albuquerque e Silva (2012), que desenvolveram estudo com o objetivo de analisar qual impacto a alteração do rating soberano brasileiro, definido pelas agências avaliadoras de rating, provocou nos retornos das ações de empresas com maior volume de negociação histórica da BM\&FBovespa, e se existem empresas mais ou menos sensíveis a essas alterações, obteve-se como resultados que as ações da Petrobrás apresentaram um desempenho acima da média das demais empresas na ocorrência de tal evento, e que as notícias positivas impactaram mais que as negativas nos retornos realizados.

Já no estudo desenvolvido por Cerqueira et al. (2012), que objetivou analisar a relação entre o preço e o retorno das ações das empresas brasileiras após a adoção das normas internacionais de Contabilidade, foi possível verificar que os resultados desse estudo denotam que a adoção inicial do custo atribuído e do impairment impactam no preço das ações, porém não foram encontrados resultados significantes relacionando às divulgações posteriores à variação no preço.

Como síntese dessas pesquisas, é possível evidenciar que há um objeto recorrente de estudo - o retorno para os acionistas -, onde o termo eficiência estava implícito nos modelos propostos e os dados da Contabilidade foram utilizados de forma predominante. Ainda há de se destacar a abordagem empírica do problema na forma quantitativa e positivista.

Sobre este estudo, tem-se o diferencial em analisar a fronteira de eficiência das empresas analisadas com a aplicação do modelo de Análise Envoltória de Dados (DEA) visando, entre outros aspectos, à evidenciação das melhores empresas sob a perspectiva da eficiência na geração de lucros e dividendos. Adicionalmente, também será possível identificar as melhores alternativas de empresas para investimentos.

\section{Metodologia da Pesquisa}

\subsection{Classificação da pesquisa}

Segundo Vergara (2000), esta pesquisa classifica-se, quanto à sua finalidade, em descritiva e metodológica, pois são apresentadas as caracterísiticas dos casos estudados na pesquisa e há o uso de métodos para a intervenção visando ao tratamento e à análise dos dados. Ainda de acordo com a autora, a pesquisa pode ser classificada, quanto aos meios de investigação, como pesquisa bibliográfica e documental, uma vez que o estudo foi desenvolvido com base em dados primários e material publicado, constituído principalmente de livros, artigos, periódicos e base de dados coletada no software Economática ${ }^{\circledR}$ e no site da BM\&FBovespa (www.bmfbovespa.com.br). A pesquisa também pode ser classificada como positivista, pois tem como um dos objetivos estudar fatos e estabelecer relação entre eles, preocupando-se em demonstrar como se produzem as relações entre esses fatos por métodos estatísticos (MARTINS; THEÓPHILO 2009).

\subsection{População e Amostra}

A população é formada pelas 22 empresas do setor da construção civil com ações negociadas na BM\&FBovespa nos anos 2009 e 2010, relacionadas no Quadro 1. 
Quadro 1 - Empresas do setor da construção civil com ações negociadas na BM\&FBovespa nos anos de 2009 e 2010

\begin{tabular}{|c|l|l|c|c|}
\hline $\mathbf{n}$ & \multicolumn{1}{|c|}{ Razão Social } & Nome de Pregão & $\begin{array}{c}\text { Faz parte do } \\
\text { Novo Mercado }\end{array}$ & $\begin{array}{c}\text { Initial Public } \\
\text { Offering - IPO }\end{array}$ \\
\hline 1 & Brookfield Incorporações S.A. & BROOKFIELD & Sim & $20 / 10 / 2006$ \\
\hline 2 & Camargo Correa Desenvolvimento Imobiliário S.A. & CC DES IMOB & Sim & $31 / 01 / 2007$ \\
\hline 3 & Cr2 Empreendimentos Imobiliários S.A. & CR2 & Sim & $20 / 04 / 2007$ \\
\hline 4 & Cyrela Brazil Realty S.A. Empreendimentos e Participações & CYRELA REALT & Sim & $20 / 09 / 2005$ \\
\hline 5 & Even Construtora e Incorporadora S.A. & EVEN & Sim & $30 / 03 / 2007$ \\
\hline 6 & Ez Tec Empreendimento e Participações S.A. & EZTEC & Sim & $21 / 06 / 2007$ \\
\hline 7 & Gafisa S.A. & GAFISA & Sim & $16 / 02 / 2006$ \\
\hline 8 & Helbor Empreendimentos S.A. & HELBOR & Sim & $26 / 10 / 2007$ \\
\hline 9 & Jhsf Participações S.A. & JHSF PART & Sim & $11 / 04 / 2007$ \\
\hline 10 & Mrv Engenharia e Participações S.A. & MRV & Sim & $24 / 07 / 2007$ \\
\hline 11 & Pdg Realty S.A. Empreendimentos e Participaç̃̃es & PDG REALT & Sim & $24 / 01 / 2007$ \\
\hline 12 & Rodobens Negócios Imobiliários S.A. & RODOBENS & Sim & $30 / 01 / 2007$ \\
\hline 13 & Rossi Residencial S.A. & ROSSI RESID & Sim & $22 / 07 / 1997$ \\
\hline 14 & Tecnisa S.A. & TECNISA & Sim & $01 / 02 / 2011$ \\
\hline 15 & Trisul Incorporadora e Construtora S.A. & TRISUL & Sim & $15 / 10 / 2007$ \\
\hline 16 & Viver Incorporadora e Construtora S.A. & VIVER & Sim & $05 / 06 / 2007$ \\
\hline 17 & Brookfield São Paulo Empreendimentos Imobiliários S.A. & BROOKFIELD & Não & $10 / 03 / 2006$ \\
\hline 18 & Cimob Participações S.A. & CC DES IMOB & Não & $09 / 04 / 2002$ \\
\hline 19 & Construtora Adolpho Lindenberg S.A. & CR2 & Não & $27 / 04 / 2004$ \\
\hline 20 & Direcional Engenharia S.A. & CYRELA REALT & Sim & $19 / 11 / 2009$ \\
\hline 21 & João Fortes Engenharia S.A. & EVEN & Não & $07 / 11 / 1999$ \\
\hline 22 & Sergen Serviços Gerais de Engenharia S.A. & EZTEC & Não & $15 / 06 / 2000$ \\
\hline Fon & & & \\
\hline
\end{tabular}

Fonte: www.bmfbovespa.com.br

Os critérios adotados para a composição da amostra foram os seguintes:

1. Fazer parte do segmento Novo Mercado

2. Ter feito IPO em data anterior a $1^{\circ}$ de janeiro de 2009.

O Novo Mercado é um segmento de listagem da BM\&FBovespa destinado à negociação de ações emitidas por empresas que se comprometem, voluntariamente, com a adoção de práticas de governança corporativa e divulgação de informações adicionais em relação ao que é exigido pela legislação.

Dessa forma, para composição da amostra foram consideradas 16 empresas (Figura 1):

Figura 1 - Composição da amostra

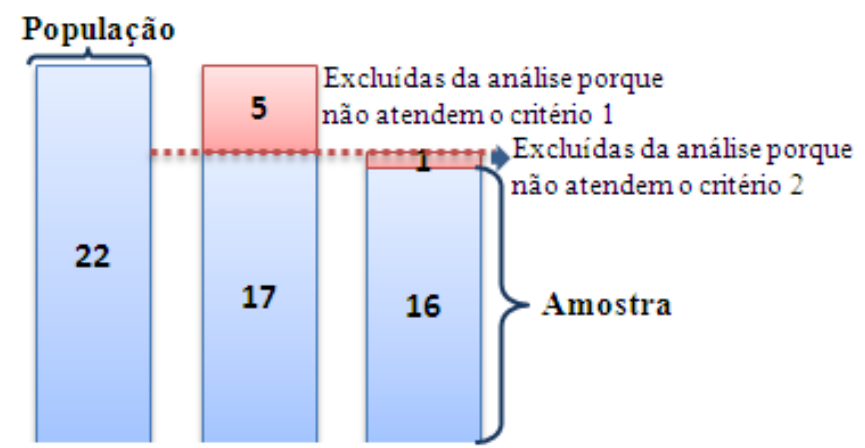

Fonte: Elaborada pelos autores.

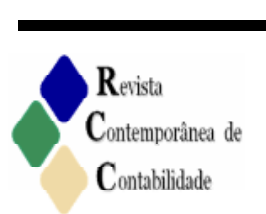




\subsection{Coleta e análise dos Dados}

Os dados foram extraídos das demonstrações contábeis consolidadas - Balanço Patrimonial, Demonstração do Resultado do Exercício e Demonstração do Valor Adicionado - obtidas por meio de coleta no software Economática ${ }^{\circledR}$ e na base de dados disponível no site da BM\&FBovespa (www.bmfbovespa.com.br).

A análise foi feita com o uso do software Microsoft Excel ${ }^{\circledR}$ para tabulação e organização dos dados e do software SIAD, para rodar o modelo DEA proposto, estabelecer a fronteira de eficiência, construir o ranking de eficiência relativa das empresas e identificar as metas de melhoria para as empresas ineficientes.

\subsection{O Modelo DEA como instrumento de intervenção da pesquisa}

A Análise Envoltória de Dados (DEA) foi desenvolvida por Charnes, Cooper e Rhodes (1978), tendo como base os estudos sobre eficiência elaborados por Debreu (1951), Koopmans (1951) e Farrel (1957), com o objetivo de calcular a eficiência relativa de unidades tomadoras de decisão, denominadas DMUs - do inglês Decision Making Units - com múltiplos insumos (inputs) e produtos (outputs).

Charnes, Cooper e Rhodes (1981) denominam a função descrita por esse programa linear como inter-envelope, uma vez que envelopa as demais funções do conjunto. Daí, o nome Data Envelopment Analysis (DEA).De acordo com Ferreira e Gomes (2009), a DEA otimiza cada observação com o intuito de se construir a Fronteira de Eficiência (Figura 2), sendo que esta consiste em uma curva discreta formada unicamente por DMUs eficientes, que envelopa a área de ineficiência, na qual se situam as unidades ineficientes.

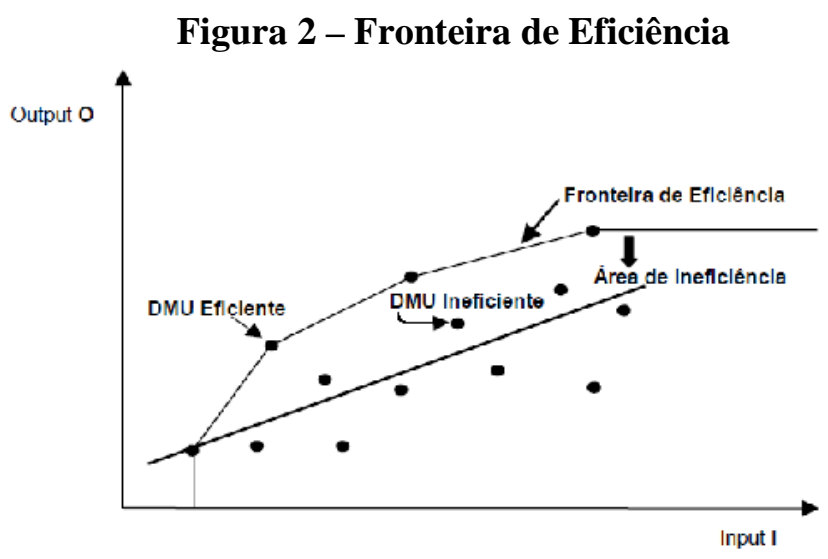

Fonte: Elaborada pelos autores.

Para o cálculo dessa fronteira de eficiência, utiliza-se a técnica de programação matemática com o objetivo de medir a eficiência em termos de distância de cada DMU da fronteira de eficiência. Essa distância da fronteira pode ser entendida como meta de melhoria, ou seja, quanto cada empresa ineficiente precisa atingir de resultados para alcançar sua(s) respectiva(s) benchmark(s) na fronteira eficiente (FERREIRA; GOMES, 2009).

Sobre o escopo de aplicação do modelo DEA, há dois modelos principais: o CCR, proposto por Charnes, Cooper e Rhodes em 1978, também conhecido como CRS (Constant 
Returns to Scale), pois pressupõe que as unidades sob análise apresentem retornos constantes de escala; e o modelo BCC, proposto por Banker, Charnes e Cooper em 1984, também conhecido como VRS (Variable Returns to Scale), pois pressupõe que as unidades sob análise apresentem retornos variáveis de escala.

Quanto ao modelo BCC, Neves Júnior et al. (2010) explicam que sua formulação pressupõe que as unidades avaliadas apresentem retornos variáveis de escala, ou seja, os retornos consideram que o acréscimo em uma unidade de insumo pode gerar um acréscimo não proporcional no volume de produtos, permitindo identificar uma diferença entre a eficiência técnica e a eficiência de escala.

Ainda com o objetivo de melhor discriminar as DMUs, Yamada et al. (1994), Entani et al. (2002) e Novaes (2002) apud Soares de Mello (2005) desenvolveram o conceito de fronteira invertida, que passou a ser utilizado em diversos trabalhos, a exemplo de Leta et al. (2005) e Angulo-Meza et al. (2005).

A fronteira invertida consiste em considerar os outputs como inputs e os inputs como outputs. Esse enfoque considera pelo menos duas interpretações: a primeira é que a fronteira consiste nas DMUs com as piores práticas gerenciais (e poderia ser chamada de fronteira ineficiente); a segunda é que essas mesmas DMUs têm as melhores práticas considerando o ponto de vista oposto (SOARES DE MELLO et al., 2003).

A Figura 3 mostra as duas fronteiras, a clássica e a invertida, para o modelo DEA BCC.

\section{Figura 3 - Fronteira de eficiência clássica e invertida}

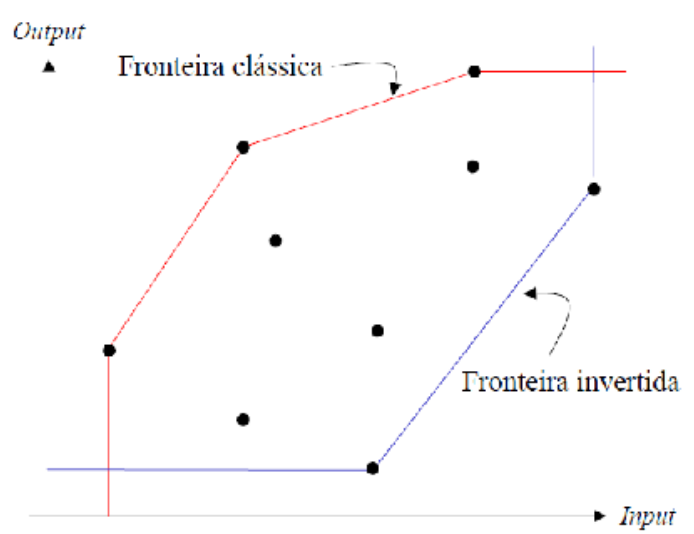

Fonte: Extraída de Angulo-Meza et al. (2005).

A utilização da fronteira invertida permite uma análise mais sofisticada do problema, uma vez que esta avalia as DMUs naquilo que elas são ineficientes, ou seja, a DMU deve se "especializar" naquilo em que ela possui excelência e não deve possuir um desempenho ruim nas outras tarefas. A fronteira invertida permite a identificação de DMUs consideradas "falsaeficientes", pois DMUs consideradas eficientes através da fronteira padrão são consideradas ineficientes através da fronteira invertida, caracterizando uma falsa eficiência.

Para uma DMU possuir alta eficiência, esta deve ter um elevado grau de pertinência em relação à fronteira otimista e baixo grau em relação à fronteira pessimista. Dessa forma, todas as variáveis são levadas em conta no índice final. Assim, não basta a DMU ter bom desempenho naquilo em que ela é melhor, também não pode ter um mau desempenho no critério em que for pior. Isso é conseguido sem a atribuição de nenhum peso subjetivo a qualquer critério (SOARES DE MELLO et al., 2003). 
Nesse sentido, uma maneira calcular e evidenciar um ranking de eficiência, conforme Angulo-Meza et al., (2005), é calculando a eficiência composta normalizada, a qual será única para cada empresa.

A eficiência composta é o resultado da análise da DMU pela fronteira padrão e invertida. De acordo com Angulo-Meza et al., (2005), o resultado é obtido pela média aritmética entre a eficiência padrão e o valor obtido da subtração da eficiência invertida pela unidade, conforme fórmula a seguir:

\section{Eficiência Composta $=$ Eficiência Padrão $+(1-$ Eficiência Invertida $) / 2$}

E a eficiência composta normalizada, de acordo com Angulo-Meza et al. (2005), é obtida dividindo o valor da eficiência composta pelo maior valor entre todos os valores de eficiência composta, conforme fórmula a seguir:

\section{Eficiência Composta Normalizada = Eficiência Composta / Max (Eficiência Composta)}

Com relação ao uso de softwares para o cálculo da fronteira de eficiência, Ferreira (2009) enumera em seu livro uma relação dos principais softwares disponíveis no mercado para rodar os modelos de DEA. Dentre esses softwares, destaca-se o Sistema Integrado de Apoio à Decisão (SIAD), que, de acordo com Angulo-Meza (2005), foi desenvolvido principalmente para resolver os problemas de programação linear da Análise Envoltória de Dados. Segundo essa mesma autora, o SIAD fornece como resultados as fronteiras de eficiência padrão, invertida, composta e composta normalizada, além dos resultados de metas de melhoria.

\subsection{Modelo DEA e as variáveis utilizadas na pesquisa}

A partir dos preceitos apresentados para os modelos DEA, definiu-se o modelo BCC com orientação a output para aplicação neste estudo. A justificativa dessa escolha é o fato de que as unidades avaliadas neste trabalho apresentam retornos variáveis de escala.

Nesse sentido, a aplicação do modelo DEA nesta pesquisa, tem o objetivo de responder à seguinte questão: "[d]ado o nível de inputs utilizado, qual o maior nível de outputs que se pode alcançar, mantendo-se o nível dos inputs constante?”.

A definição das variáveis para compor o modelo também foi feita seguindo os conceitos e as recomendações constantes na revisão da literatura, na qual define que o retorno para o acionista é igual a dividendo mais ganho ou perda de capital.

Dessa forma, o modelo BCC proposto com orientação a maximizar outputs é ilustrado na Figura 4.

\section{Figura 4 - Modelo DEA/BCC}

Input: $\quad$ Outputs:

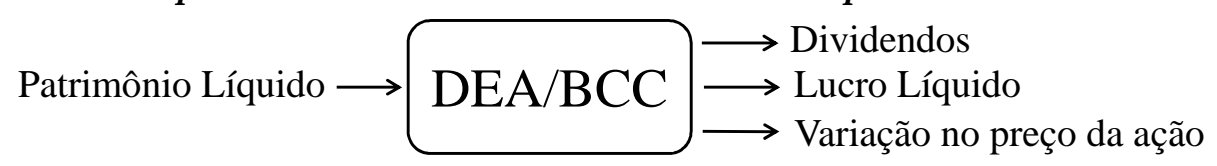

Fonte: Adaptado de Ferreira e Gomes (2009).

51 ISSN 2175-8069, UFSC, Florianópolis, v.9, n.18, p.41-62, jul./dez., 2012 
Feita a definição das DMUs, do modelo DEA e das variáveis, chega-se à base de dados a ser utilizada para a operacionalização da DEA.

Na Tabela 1 é apresentado o banco de dados com as 16 DMUs e as variáveis inputs e outputs para os anos de 2009 e 2010 , respectivamente.

Tabela 1 - DMUs e variáveis

\begin{tabular}{|c|c|c|c|c|c|c|c|c|}
\hline \multirow{3}{*}{$\begin{array}{c}\text { DMUs } \\
\text { (Empresas) }\end{array}$} & \multirow{2}{*}{\multicolumn{2}{|c|}{$\begin{array}{c}\text { Input } \\
\text { Patrimônio Líquido (R\$ } \\
\text { Mil) }\end{array}$}} & \multicolumn{6}{|c|}{ Outputs } \\
\hline & & & \multicolumn{2}{|c|}{ Dividendos (R $\$$ Mil) } & \multicolumn{2}{|c|}{$\begin{array}{c}\text { Lucro Líquido (R\$ } \\
\text { Mil) }\end{array}$} & \multicolumn{2}{|c|}{$\begin{array}{l}\text { Variação preço da } \\
\text { ação no ano }\end{array}$} \\
\hline & 2009 & 2010 & 2009 & 2010 & 2009 & 2010 & 2009 & 2010 \\
\hline BROO & 2.417 .256 & 2.701 .894 & 47.948 & 103.645 & 201.887 & 363.669 & $228,86 \%$ & $12,20 \%$ \\
\hline CC DES & 675.369 & 777.840 & 13.777 & 31.740 & 58.007 & 143.195 & $119,77 \%$ & $45,57 \%$ \\
\hline CR2 & 421.481 & 431.120 & 4.079 & 11.595 & 15.096 & 46.954 & $85,37 \%$ & $29,94 \%$ \\
\hline CYRELA & 4.105 .383 & 4.681 .937 & 198.907 & 142.559 & 729.349 & 600.249 & $168,52 \%$ & $-8,96 \%$ \\
\hline EVEN & 917.852 & 1.409 .837 & 29.733 & 59.967 & 124.454 & 252.491 & $197,14 \%$ & $3,75 \%$ \\
\hline EZTEC & 924.900 & 1.116 .642 & 38.696 & 57.887 & 162.931 & 243.734 & $275,95 \%$ & $69,56 \%$ \\
\hline GAFISA & 2.384 .181 & 3.783 .669 & 54.479 & 102.767 & 213.540 & 416.050 & $169,27 \%$ & $-14,19 \%$ \\
\hline HELBOR & 429.833 & 727.827 & 22.421 & 51.886 & 78.670 & 182.058 & $396,25 \%$ & $72,71 \%$ \\
\hline JHSF PART & 942.776 & 1.078 .469 & 30.000 & 100.000 & 149.171 & 212.551 & $149,20 \%$ & $0,25 \%$ \\
\hline MRV & 2.516 .524 & 3.052 .750 & 82.513 & 86.957 & 347.422 & 634.488 & $332,35 \%$ & $14,93 \%$ \\
\hline PDG REALT & 2.960 .998 & 5.964 .848 & 80.306 & 187.519 & 338.132 & 789.552 & $211,21 \%$ & $29,77 \%$ \\
\hline RODOI & 622.833 & 677.508 & 6.595 & 17.017 & 27.770 & 71.663 & $137,27 \%$ & $-6,27 \%$ \\
\hline ROSSI RESID & 2.283 .413 & 2.522 .358 & 51.800 & 83.071 & 218.099 & 349.770 & $312,84 \%$ & $-2,48 \%$ \\
\hline TECNISA & 983.111 & 1.195 .384 & 26.252 & 47.512 & 110.536 & 200.048 & $212,59 \%$ & $7,73 \%$ \\
\hline TRISL & 463.024 & 508.413 & 10.767 & 9.300 & 51.516 & 39.159 & $144,19 \%$ & $23,65 \%$ \\
\hline VIVER & 793.946 & 1.120 .831 & - & & 12.973 & 67.373 & $108,38 \%$ & $-1,71 \%$ \\
\hline Máximo & 4.105 .383 & 5.964 .848 & 198.907 & 187.519 & 729.349 & 789.552 & $396,25 \%$ & $72,71 \%$ \\
\hline Mínimo & 421.481 & 431.120 & - & & 12.973 & 39.159 & $85,37 \%$ & $-14,19 \%$ \\
\hline Média & 1.490 .180 & 1.984 .457 & 43.642 & 68.339 & 177.472 & 288.312 & $203,07 \%$ & $17,28 \%$ \\
\hline Desvio padrão & 1.118 .637 & 1.651 .458 & 48.398 & $51.603,17$ & 180.157 & 225.001 & $87,58 \%$ & $26,51 \%$ \\
\hline
\end{tabular}

Fonte: Elaboração dos autores com base de dados do Economática ${ }^{\circledR}$ e BM\&Fbovespa.

Essas variáveis foram confirmadas como significativas para o modelo, conforme demonstrado na análise de correlação (Tabelas 2 e 3):

Tabela 2 - Matriz de correlação entre as variáveis - 2009

\begin{tabular}{l|cccc}
\hline \multicolumn{1}{c|}{$\mathbf{2 0 0 9}$} & Patrimônio Líquido & Dividendos & Lucro Líquido & $\begin{array}{c}\text { Variação preço } \\
\text { da ação no ano }\end{array}$ \\
\hline Patrimônio Líquido & 1,00 & & & \\
\hline Dividendos & 0,90 & 1,00 & & \\
\hline Lucro Líquido & 0,92 & 1,00 & 1,00 & 1,00 \\
\hline Variação preço da ação no ano & 0,20 & 0,20 & 0,22 & \\
\hline
\end{tabular}

Fonte: Elaborada pelos autores.

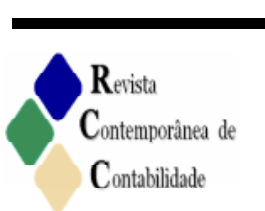


Análise da eficiência na geração de retorno aos acionistas das empresas do setor da construção civil com...

Tabela 3 - Matriz de correlação entre as variáveis - 2010

\begin{tabular}{l|cccc}
\hline \multicolumn{1}{c|}{$\mathbf{2 0 1 0}$} & Patrimônio Líquido & Dividendos & Lucro Líquido & $\begin{array}{l}\text { Variação preço } \\
\text { da ação no ano }\end{array}$ \\
\hline Patrimônio Líquido & 1,00 & & & \\
\hline Dividendos & 0,91 & 1,00 & & \\
\hline Lucro Líquido & 0,94 & 0,91 & 1,00 & \\
\hline Variação preço da ação no ano & $-0,30$ & $-0,16$ & $-0,15$ & 1,00 \\
\hline
\end{tabular}

Fonte: Elaborada pelos autores.

A análise da correlação é uma análise de dados amostrais cujo objetivo é saber como e se duas ou mais variáveis estão relacionadas umas com as outras. Ela gera um número que resume o grau de relacionamento entre duas variáveis, que oscila entre $-1,0$ e $+1,0$. O grau de relacionamento igual a +1 significa uma correlação perfeita e positiva, e o grau -1 significa uma correlação negativa perfeita entre as duas variáveis, ou seja, se uma aumenta, a outra sempre diminui. Se o número for 0,70 para mais, indica uma forte correlação; 0,30 a 0,70, positivo ou negativo, indica correlação moderada; e 0,30 a 0,00 , fraca correlação. (STEVENSON, 1986).

Verifica-se, nos dois anos, uma forte correlação positiva entre as variáveis Patrimônio Líquido, Dividendos e Lucro Líquido. Já a variável Preço da Ação em relação às demais variáveis apresentou correlação positiva fraca no de 2009, e negativa fraca no de 2010.

\subsection{Protocolo de pesquisa}

Os procedimentos desta pesquisa são divididos em quatro etapas. A Figura 5 apresenta de forma sistematizada o protocolo de pesquisa:

Figura 5 - Protocolo de pesquisa
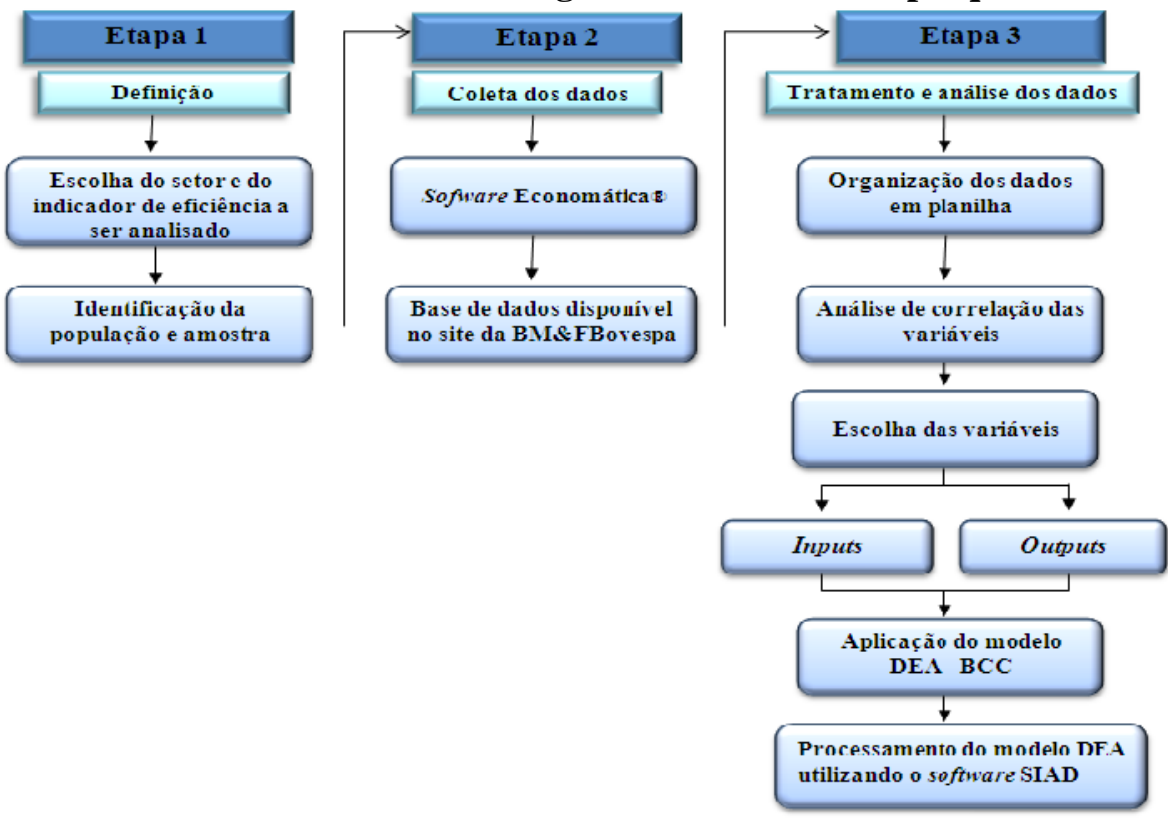

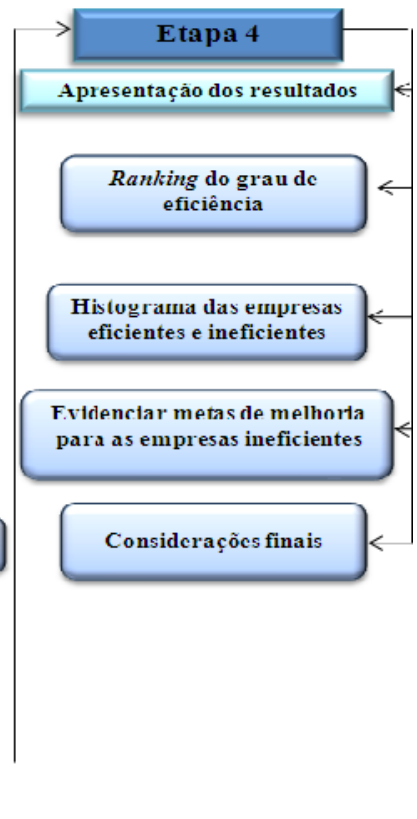

Fonte: Adaptado Yin (1989). 
Na etapa 1, foi feita a definição do setor e do indicador de eficiência a ser analisado, bem como a identificação da população e da amostra; portanto foi o momento da delimitação do estudo.

Na etapa 2, procedeu-se à coleta dos dados no Software Economática ${ }^{\circledR}$ e na base de dados disponível no site da BM\&FBovespa (www.bmfbovespa.com.br).

$\mathrm{Na}$ etapa 3, realizou-se o tratamento e a organização dados coletados em planilhas no software Microsoft Excel ${ }^{\circledR}$. Posteriormente aplicou-se a análise de correlação para verificar o grau de relacionamento entre as variáveis inputs e outputs. Em seguida concluiu-se essa etapa analisando as variáveis por meio do modelo DEA-BCC, através do software SIAD.

$\mathrm{Na}$ etapa 4, foram apresentados os resultados com a construção do ranking do grau de eficiência das empresas, o histograma das empresas eficientes e ineficientes e a proposição das metas de melhoria para as ineficientes alcançarem a eficiência, concluindo com as considerações finais.

\section{Resultados}

O modelo DEA/BCC orientado a output foi aplicado à base de dados apresentada na Tabela 1, com a utilização do software SIAD, gerando os resultados que são apresentados ao longo desta seção em forma de tabelas.

\subsection{Fronteira e ranking de eficiência}

Na Tabela 4 são apresentados os resultados completos das 16 DMUs nos dois anos analisados, contendo os escores de eficiência das fronteiras padrão, invertida, composta e composta normalizada, respectivamente.

Tabela 4 - Escore de eficiência nos anos de 2009 e 2010

\begin{tabular}{|c|c|c|c|c|c|c|c|c|}
\hline \multirow{2}{*}{ DMU } & \multicolumn{4}{|c|}{2009} & \multicolumn{4}{|c|}{2010} \\
\hline & Padrão & Invertida & Composta & Normalizada & Padrão & Invertida & Composta & Normalizada \\
\hline BROOKFIELD & $68,2 \%$ & $100,0 \%$ & $34,1 \%$ & $38,3 \%$ & $85,4 \%$ & $75,5 \%$ & $55,0 \%$ & $63,6 \%$ \\
\hline CC DES IMOB & $47,5 \%$ & $79,4 \%$ & $34,0 \%$ & $38,2 \%$ & $74,7 \%$ & $36,0 \%$ & $69,3 \%$ & $80,2 \%$ \\
\hline $\mathrm{CR} 2$ & $100,0 \%$ & $100,0 \%$ & $50,0 \%$ & $56,1 \%$ & $100,0 \%$ & $83,4 \%$ & $58,3 \%$ & $67,4 \%$ \\
\hline CYRELA & $100,0 \%$ & $100,0 \%$ & $50,0 \%$ & $56,1 \%$ & $90,4 \%$ & $100,0 \%$ & $45,2 \%$ & $52,2 \%$ \\
\hline EVEN & $75,4 \%$ & $53,5 \%$ & $61,0 \%$ & $68,3 \%$ & $82,6 \%$ & $41,7 \%$ & $70,5 \%$ & $81,5 \%$ \\
\hline EZTEC & $98,0 \%$ & $38,6 \%$ & $79,7 \%$ & $89,3 \%$ & $100,0 \%$ & $27,6 \%$ & $86,2 \%$ & $99,7 \%$ \\
\hline GAFISA & $55,9 \%$ & $100,0 \%$ & $28,0 \%$ & $31,3 \%$ & $73,5 \%$ & $100,0 \%$ & $36,8 \%$ & $42,5 \%$ \\
\hline HELBOR & $100,0 \%$ & $21,6 \%$ & $89,2 \%$ & $100,0 \%$ & $100,0 \%$ & $27,1 \%$ & $86,5 \%$ & $100,0 \%$ \\
\hline JHSF PART & $88,0 \%$ & $69,5 \%$ & $59,2 \%$ & $66,4 \%$ & $100,0 \%$ & $31,8 \%$ & $84,1 \%$ & $97,2 \%$ \\
\hline MRV & $100,0 \%$ & $66,2 \%$ & $66,9 \%$ & $75,0 \%$ & $100,0 \%$ & $85,7 \%$ & $57,1 \%$ & $66,1 \%$ \\
\hline PDG REALT & $74,1 \%$ & $100,0 \%$ & $37,0 \%$ & $41,5 \%$ & $100,0 \%$ & $100,0 \%$ & $50,0 \%$ & $57,8 \%$ \\
\hline RODOBENS & $35,2 \%$ & $70,5 \%$ & $32,4 \%$ & $36,3 \%$ & $45,0 \%$ & $100,0 \%$ & $22,5 \%$ & $26,0 \%$ \\
\hline ROSSI RESID & $92,2 \%$ & $85,4 \%$ & $53,4 \%$ & $59,8 \%$ & $77,1 \%$ & $100,0 \%$ & $38,6 \%$ & $44,6 \%$ \\
\hline TECNISA & $62,6 \%$ & $52,2 \%$ & $55,2 \%$ & $61,9 \%$ & $74,4 \%$ & $38,6 \%$ & $67,9 \%$ & $78,6 \%$ \\
\hline TRISUL & $60,9 \%$ & $59,9 \%$ & $50,5 \%$ & $56,7 \%$ & $57,6 \%$ & $100,0 \%$ & $28,8 \%$ & $33,3 \%$ \\
\hline VIVER & $27,4 \%$ & $100,0 \%$ & $13,7 \%$ & $15,3 \%$ & $26,1 \%$ & $100,0 \%$ & $13,0 \%$ & $15,1 \%$ \\
\hline Eficiente(s) (s) & 4 & 6 & 1 & 1 & 6 & 7 & 1 & 1 \\
\hline Ineficientes & 12 & 10 & 15 & 15 & 10 & 9 & 15 & 15 \\
\hline
\end{tabular}

Fonte: Dados da pesquisa.

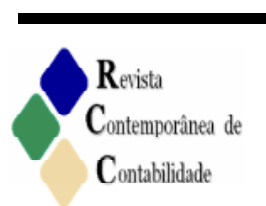


De acordo com os escores de eficiência apresentados na coluna referente à fronteira padrão fica evidenciado que a fronteira de eficiência na geração de retorno ao acionista das empresas do setor da construção civil com ações negociadas na BM\&FBovespa para o ano de 2009 é composta pelas empresas CR2, CYRELA REALT, HELBOR e MRV, e para o ano de 2010 é composta pelas empresas CR2, EZTEC, HELBOR, JHSF, MRV e PDG REALT.

Esses resultados permitiram identificar as empresas que apresentaram desempenho eficiente sob a perspectiva da otimização - menor uso de recursos próprios (patrimônio líquido) com o máximo de retorno para os acionistas (lucro líquido, dividendos e variação do preço de ações) -, o que corrobora com as afirmações de Assaf Neto (2008), Gitman (2004) e Iudicíbus (2010), em que há o pressuposto da busca de eficiência pela obtenção do máximo de resultados de forma a maximizar a riqueza dos acionistas.

Contudo, com base nos fundamentos teóricos do modelo DEA, observa-se que a fronteira padrão não permitiria identificar, no conjunto analisado, qual foi a empresa mais eficiente, o que impossibilitaria alcançar um dos objetivos específicos que é a construção de um ranking de eficiência relativa das empresas, pois, para tanto, seria necessário fazer o desempate entre as empresas consideradas eficientes, confirmando assim o exposto na fundamentação teórica de que isso pode se tornar um problema quando se pretende tomar uma decisão entre a melhor opção de investimento entre as empresas eficientes.

Nessa questão, há a contribuição do estudo de Soares de Mello (2005) que propõe o uso da fronteira de eficiência invertida para identificar empresas que inicialmente são apresentadas como eficientes, contudo podem representar uma falsa eficiência.

Portanto, a discriminação da eficiência é realizada com base na aplicação da fronteira invertida, pois todas as empresas eficientes na fronteira padrão teoricamente passariam ao status de ineficientes na segunda fronteira e vice-versa. Como a DEA atribui um escore específico para as DMUs com pertença à área de ineficiência então se teria uma maneira de desempatar as empresas consideradas $100 \%$ eficientes pela fronteira padrão, não fosse pelo fato de algumas DMUs eficientes na primeira fronteira também serem consideradas eficientes na segunda fronteira, como foi o caso das empresas CR2 e CYRELA REALT no ano de 2009, e PDG REALT no ano de 2010, confirmando mais uma vez aquilo que foi dito na fundamentação teórica do modelo DEA sobre a ocorrência de DMUs com "falsas eficiências" na fronteira invertida.

Para a construção do ranking calculou-se então a fronteira composta e a fronteira composta normalizada, conforme os fundamentos apresentados por Soares de Mello (2005), chegando-se aos resultados apresentados na Tabela 5.

Tabela 5 - Ranking de eficiência normalizada - 2009 e 2010

\begin{tabular}{|c|c|c|c|c|c|}
\hline \multicolumn{3}{|c|}{2009} & \multicolumn{3}{|c|}{2010} \\
\hline Posição & DMU & $\begin{array}{c}\text { Eficiência } \\
\text { Normalizada }\end{array}$ & Posição & DMU & $\begin{array}{c}\text { Eficiência } \\
\text { Normalizada }\end{array}$ \\
\hline $1^{\circ}$ & HELBOR & $100,0 \%$ & $1^{\mathrm{o}} \quad\left(\operatorname{era} 1^{o}\right)$ & HELBOR & $100,0 \%$ \\
\hline $2^{\circ}$ & EZTEC & $89,3 \%$ & $\left(\operatorname{era} 2^{\circ}\right)$ & EZTEC & $99,7 \%$ \\
\hline $3^{\circ}$ & MRV & $75,0 \%$ & $3^{\circ} \quad\left(\operatorname{era~} 5^{\circ}\right)$ & JHSF & $97,2 \%$ \\
\hline $4^{\circ}$ & EVEN & $68,3 \%$ & $4^{\circ} \quad\left(\operatorname{era} 4^{\circ}\right)$ & EVEN & $81,5 \%$ \\
\hline $5^{\circ}$ & JHSF PART & $66,4 \%$ & $5^{\circ} \quad\left(\operatorname{era} 13^{\circ}\right)$ & CC DES. IMOB & $80,2 \%$ \\
\hline $6^{\circ}$ & TECNISA & $61,9 \%$ & $6^{\circ} \quad\left(\right.$ era $\left.6^{\circ}\right)$ & TECNISA & $78,6 \%$ \\
\hline $7^{\circ}$ & ROSSI & $59,8 \%$ & $7^{\circ} \quad\left(\operatorname{era} 9^{\circ}\right)$ & $\mathrm{CR} 2$ & $67,4 \%$ \\
\hline $8^{\circ}$ & TRISUL & $56,7 \%$ & $8^{\circ} \quad\left(\operatorname{era} 3^{\circ}\right)$ & MRV & $66,1 \%$ \\
\hline $9^{\circ}$ & CR2 & $56,1 \%$ & $9^{\circ} \quad\left(\operatorname{era} 12^{\circ}\right)$ & BROOKFIELD & $63,6 \%$ \\
\hline
\end{tabular}


Idalberto José das Neves Júnior, Simone Alves Moreira, Erivaldo dos Santos Vasconcelos e Juliano Lima Brito

\begin{tabular}{lll|llll}
\hline $10^{\circ}$ & CYRELA REALT & $56,1 \%$ & $10^{\circ}$ & $\left(\right.$ era $\left.11^{\circ}\right)$ & PDG REALT & $57,8 \%$ \\
$11^{\circ}$ & PDG REALT & $41,5 \%$ & $11^{\circ}$ & $\left(\right.$ era $\left.10^{\circ}\right)$ & CYRELA REALT & $52,2 \%$ \\
$12^{\circ}$ & BROOKFIELD & $38,3 \%$ & $12^{\circ}$ & $\left(\right.$ era $\left.7^{\circ}\right)$ & ROSSI & $44,6 \%$ \\
$13^{\circ}$ & CC DES. IMOB & $38,2 \%$ & $13^{\circ}$ & $\left(\right.$ era $\left.15^{\circ}\right)$ & GAFISA & $42,5 \%$ \\
$14^{\circ}$ & RODOBENS & $36,3 \%$ & $14^{\circ}$ & $\left(\right.$ era $\left.8^{\circ}\right)$ & TRISUL & $33,3 \%$ \\
$15^{\circ}$ & GAFISA & $31,3 \%$ & $15^{\circ}\left(\right.$ era $\left.14^{\circ}\right)$ & RODOBENS & $26,0 \%$ \\
$16^{\circ}$ & VIVER & $15,3 \%$ & $16^{\circ}$ & $\left(\right.$ era $\left.16^{\circ}\right)$ & VIVER & $15,1 \%$ \\
\hline
\end{tabular}

Fonte: Dados da pesquisa.

Baseado no ranking, é possível afirmar que a empresa HELBOR foi a mais eficiente em gerar retorno aos acionistas nos dois anos analisados, seguida da EZTEC que, em 2009, já ocupava a segunda posição com 89,3\% no grau de eficiência, e em 2010 teve uma atribuição de eficiência de $99,7 \%$, ficando muito próxima da primeira colocada. Por outro lado, a VIVER foi a menos eficiente nos dois anos analisados.

Essa constatação corrobora com os preceitos apresentados por Assaf Neto (2010) à medida que a identificação da empresa mais eficiente pode favorecer a agregação de valor para a decisão do investidor que busca a melhor alternativa de alocação de recursos, uma vez que o mercado competitivo reconhece as empresas eficientes.

Esses resultados - sobre a perspectiva do conceito de eficiência - confirmam a afirmativa de Hendriksen et al. (1999) que define a eficiência na utilização do capital dos acionistas visando à obtenção do máximo de resultados com um mínimo de recursos.

Adicionalmente, ao se realizar um comparativo do ranking pelo escore de eficiência normalizada entre os anos 2009 e 2010, observa-se que, das dezesseis DMUs, cinco mantiveram as mesmas posições relativas, seis subiram de posição e cinco caíram. Tanto as empresas que mantiveram suas posições no ranking quanto as que subiram de posição, fizeram isso porque aumentaram também o seu grau relativo de eficiência, com exceção da HELBOR que já era $100 \%$ eficiente.

Verifica-se que as maiores variações positivas no grau de eficiência ocorreram com as empresas CC DES. IMOB, BROOKFIELD e JHSF, o que pode ser justificado pelo aumento significativo nos valores das variáveis outputs dessas DMUs, conforme pode ser consultado na Tabela 1 .

Já as maiores variações negativas ocorreram com as empresas TRISUL e ROSSI, que, por sua vez, podem ser justificadas pela redução nos valores das suas variáveis outputs, conforme também pode ser consultado na Tabela 1.

Quanto à empresa CR2, que em 2009 ficou empatada com a CYRELA REALT, com grau de eficiência de $56,1 \%$, aumentou o grau de eficiência para $67,4 \%$, enquanto que a CYRELA REALT caiu para um grau de 52,2\%.

Sobre o estudo dessas variáveis, é importante destacar que a análise da correlação delas evidenciou o uso apropriado dos inputs e outputs, em especial, entre os componentes patrimônio líquido (input) e os outputs lucro líquido e dividendos (Tabelas 3 e 4). Ainda deve ser ressaltado o uso dessas variáveis como componentes dos indicadores de eficiência propostos para a análise do retorno aos acionistas, o que corrobora os índices apresentados por Braga (1989), Martins e Assaf Neto (1996), Pereira da Silva (1997), Iudícibus (2000) e Matarazzo (2010), e confirmados por Krauter (2006).

Com relação aos resultados encontrados neste estudo e os publicados em pesquisas similares, há o destaque pelo uso comum das informações contábeis (patrimônio líquido, lucro líquido e dividendos) e os resultados da correlação desta pesquisa, o que permitiu corroborar os resultados empíricos comprovados no estudo realizado por Lopes e Galdi

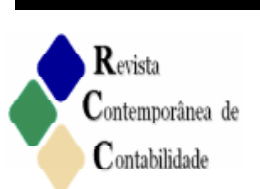


(2010) que evidenciou a relevância das informações contábeis no retorno das ações no mercado brasileiro.

No entanto, quanto ao uso da variável dividendos, ao contrastar os resultados desta pesquisa com os de Bueno (2002), foi possível identificar que, ao contrário do estudo desse pesquisador, os realizados neste trabalho evidenciaram que os dividendos obtiveram uma alta correlação com as variáveis lucro líquido e patrimônio líquido e também contribuiu para a avaliação de eficiência para o modelo DEA proposto neste estudo. Ainda sobre a variável dividendos, é possível inferir que essa variável - como descrito por Hendriksen et al. (1999) pode ser associada à gestão eficiente de empresas sobre a perspectiva do uso de capital e fluxo futuro de dividendos.

\subsection{Metas de melhoria}

Com base na análise eficiência pela fronteira padrão, identificaram-se as metas de melhoria para as empresas consideradas ineficientes alcançarem a eficiência, as quais são apresentadas na Tabela 6 para o ano de 2009 e Tabela 7 para o ano de 2010.

Tabela 6 - Metas de melhoria no ano de 2009

\begin{tabular}{l|rrr|rcc|cc}
\hline \multicolumn{1}{c|}{ 2009 } & \multicolumn{3}{c|}{ Dividendos (R\$ Mil) } & \multicolumn{2}{c}{ Lucro Líquido (R\$ Mil) } & \multicolumn{2}{c}{ Variação preço da } \\
\hline \multicolumn{1}{c}{ DMU } & \multicolumn{1}{c|}{ Atual } & \multicolumn{1}{c}{ Meta } & Aumentar & \multicolumn{1}{c}{ Atual } & \multicolumn{1}{c}{ Meta } & Aumentar & Atual & Meta \\
\hline BROOKFIELD & 47.948 & 79.654 & $66 \%$ & 201.887 & 334.636 & $66 \%$ & $228,86 \%$ & 335,3 \\
CC DES IMOB & 13.777 & 34.211 & $148 \%$ & 58.007 & 122.137 & $111 \%$ & $119,77 \%$ & 381,0 \\
CR2 & 4.079 & 4.079 & - & 15.096 & 15.096 & - & $85,37 \%$ & 85,37 \\
CYRELA & 198.907 & 198.907 & - & 729.349 & 729.349 & - & $168,52 \%$ & 168,5 \\
EVEN & 29.733 & 45.854 & $54 \%$ & 124.454 & 165.063 & $33 \%$ & $197,14 \%$ & 366,0 \\
EZTEC & 38.696 & 46.192 & $19 \%$ & 162.931 & 166.311 & $2 \%$ & $275,95 \%$ & 365,5 \\
GAFISA & 54.479 & 99.290 & $82 \%$ & 213.540 & 382.049 & $79 \%$ & $169,27 \%$ & 302,8 \\
HELBOR & 22.421 & 22.421 & - & 78.670 & 78.670 & - & $396,25 \%$ & 396,2 \\
JHSF & 30.000 & 47.051 & $57 \%$ & 149.171 & 169.475 & $14 \%$ & $149,20 \%$ & 364,4 \\
MRV & 82.513 & 82.513 & - & 347.422 & 347.422 & - & $332,35 \%$ & 332,3 \\
PDG REALT & 80.306 & 115.940 & $44 \%$ & 338.132 & 456.439 & $35 \%$ & $211,21 \%$ & 285,1 \\
RODOBENS & 6.595 & 27.979 & $324 \%$ & 27.770 & 103.527 & $273 \%$ & $137,27 \%$ & 390,3 \\
ROSSI & 51.800 & 75.800 & $46 \%$ & 218.099 & 317.398 & $46 \%$ & $312,84 \%$ & 339,4 \\
TECNISA & 26.252 & 48.987 & $87 \%$ & 110.536 & 176.616 & $60 \%$ & $212,59 \%$ & 361,9 \\
TRISUL & 10.767 & 24.015 & $123 \%$ & 51.516 & 84.545 & $64 \%$ & $144,19 \%$ & 394,1 \\
VIVER & \multicolumn{2}{c}{22.421} & - & 12.973 & 78.670 & $506 \%$ & $108,38 \%$ & 396,2 \\
\hline
\end{tabular}

Fonte: Dados da pesquisa.

Tabela 7 - Metas de Melhoria no ano de 2010

\begin{tabular}{|c|c|c|c|c|c|c|c|c|}
\hline \multirow{2}{*}{$\begin{array}{c}2010 \\
\text { DMU }\end{array}$} & \multicolumn{3}{|c|}{ Dividendos (R\$ Mil) } & \multicolumn{3}{|c|}{ Lucro Líquido (R\$ Mil) } & \multicolumn{2}{|c|}{ Variação preço da ação no ano } \\
\hline & Atual & Meta & Aumentar & Atual & Meta & Aumentar & Atual & Meta \\
\hline BROOKFIELD & 103.645 & 121.430 & $17 \%$ & 363.669 & 426.072 & $17 \%$ & $12,20 \%$ & $14,30 \%$ \\
\hline CC DES IMOB & 31.740 & 52.640 & $66 \%$ & 143.195 & 191.791 & $34 \%$ & $45,57 \%$ & $71,47 \%$ \\
\hline CR2 & 11.595 & 11.595 & - & 46.954 & 46.954 & - & $29,94 \%$ & $29,94 \%$ \\
\hline CYRELA REALT & 142.559 & 157.792 & $11 \%$ & 600.249 & 664.387 & 0,11 & $-8,96 \%$ & $22,40 \%$ \\
\hline EVEN & 59.967 & 72.582 & $21 \%$ & 252.491 & 305.605 & $21 \%$ & $3,75 \%$ & $40,27 \%$ \\
\hline EZTEC & 57.887 & 57.887 & - & 243.734 & 243.734 & $0 \%$ & $69,56 \%$ & $69,56 \%$ \\
\hline GAFISA & 102.767 & 139.770 & $36 \%$ & 416.050 & 565.857 & $36 \%$ & $-14,19 \%$ & $17,09 \%$ \\
\hline HELBOR & 51.886 & 51.886 & - & 182.058 & 182.058 & - & $72,71 \%$ & $72,71 \%$ \\
\hline JHSF & 100.000 & 100.000 & - & 212.551 & 212.551 & - & $0,25 \%$ & $0,25 \%$ \\
\hline MRV & 86.957 & 86.957 & - & 634.488 & 634.488 & - & $14,93 \%$ & $14,93 \%$ \\
\hline PDG REALT & 187.519 & 187.519 & - & 789.552 & 789.552 & - & $29,77 \%$ & $29,77 \%$ \\
\hline
\end{tabular}


Idalberto José das Neves Júnior, Simone Alves Moreira, Erivaldo dos Santos Vasconcelos e Juliano Lima Brito

\begin{tabular}{l|ccc|rrr|rr}
\hline & & & & & & & \\
RODOBENS & 17.017 & 45.053 & $165 \%$ & 71.663 & 159.146 & $122 \%$ & $-6,27 \%$ & $65,46 \%$ \\
ROSSI & 83.071 & 107.752 & $30 \%$ & 349.770 & 453.689 & $30 \%$ & $-2,48 \%$ & $10,00 \%$ \\
TECNISA & 47.512 & 63.826 & $34 \%$ & 200.048 & 268.738 & $34 \%$ & $7,73 \%$ & $53,82 \%$ \\
TRISUL & 9.300 & 22.091 & $138 \%$ & 39.159 & 82.149 & $110 \%$ & $23,65 \%$ & $41,08 \%$ \\
VIVER & - & 57.814 & - & 67.373 & 258.537 & $284 \%$ & $-1,71 \%$ & $62,95 \%$ \\
\hline
\end{tabular}

Fonte: Dados da pesquisa.

Com base nesses dados, tem-se, por exemplo, que a empresa VIVER, pior colocada no ranking de eficiência padrão em 2009, alcançaria a fronteira de eficiência se, mantendo o mesmo valor da variável "Patrimônio Líquido", aumentasse o valor da variável Dividendos para $\mathrm{R} \$ 22.421 .000,00$, o valor da variável Lucro Líquido para $\mathrm{R} \$ 78.670 .000,00$ e o valor da variável Variação no preço da ação no ano para 396,25\%.

Já a empresa TRISUL, segunda pior colocada no ranking de eficiência padrão em 2009, alcançaria a fronteira de eficiência se, mantendo o mesmo valor de Patrimônio Líquido, o valor da variável Dividendos para $\mathrm{R} \$ 24.015 .999,00$, o valor da variável Lucro Líquido para $\mathrm{R}$ \$ 84.545.000,00 e o valor da variável Variação no preço da ação no ano para 394,19\%.

A empresa EZTEC, por outro lado, que em 2009 está relativamente próxima à fronteira de eficiência, alcançaria isso se, mantendo o mesmo valor de input, aumentasse o valor da variável Dividendos para $\mathrm{R} \$ 46.192 .000,00$, o valor da variável Lucro Líquido para $\mathrm{R} \$ 166.311 .000,00$ e o valor da variável Variação no preço da ação no ano para $365,57 \%$.

Esse mesmo raciocínio é aplicado para as demais empresas ineficientes, tanto no ano de 2009, quanto no ano de 2010.

\section{Considerações Finais}

Analisou-se, neste trabalho, a eficiência das empresas do setor da construção civil em gerar retorno aos acionistas nos anos de 2009 e 2010, utilizando a DEA, considerando o Patrimônio Líquido como variável input, e o lucro líquido, os dividendos e a variação no preço da ação, como variáveis outputs.

Quanto à utilização da metodologia fronteira invertida, apresentada como proposta na fundamentação teórica do modelo DEA, como forma de resolver os casos em que se deseja uma discriminação entre as DMUs eficientes, pode-se afirmar que ela responde satisfatoriamente às necessidades enfrentadas por um interessado em desenvolver estudos com base na DEA.

Com base nas fundamentações e nos resultados obtidos, pode-se afirmar que o problema de pesquisa formulado na introdução foi plenamente respondido, e os objetivos foram alcançados, uma vez que foi possível evidenciar a fronteira de eficiência das empresas, bem como identificar as eficientes e ineficientes, construir o ranking e ainda evidenciar metas de melhoria para as empresas ineficientes alcançarem a eficiência.

Como principal resultado prático desse estudo foi possível identificar que a empresa HBOR foi a mais eficiente em gerar retorno ao acionista dentro do grupo analisado, enquanto a VIVER, foi a menos eficiente.

Em 2010, percebe-se que a maioria das empresas aumentou significativamente a eficiência, o que parece ir ao encontro do que foi dito na introdução sobre a evolução do Valor Adicionado Bruto (VAB) do setor, o qual, de acordo com a CBIC, foi 7,9\% em 2008, 8,3\% em 2009 e 11,6\% em 2010. Ou seja, a variação de 2008 para 2009 foi de apenas 0,4\%,

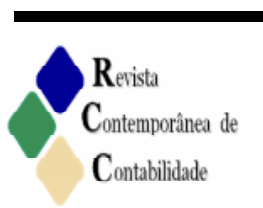


enquanto de 2009 para 2010 foi de 3,30\%. Além disso, os resultados encontrados também parecem ir ao encontro da fundamentação teórica ao afirmar que, para a empresa ser eficiente, precisa gerar retorno aos acionistas.

Contudo, como limitação do estudo, tem-se que os escores de eficiência calculados pela DEA são relativos ao conjunto de DMUs, aos inputs e outputs considerados e ao modelo utilizado, sendo que qualquer alteração nesse conjunto e qualquer retirada ou inclusão de variáveis ou mudança de modelo pode interferir no resultado, por isso não é possível a extrapolação de suas conclusões.

Ao evidenciar a eficiência ou não das empresas, este estudo pode trazer uma contribuição tanto aos acionistas correntes ou potenciais, quanto às empresas. Àqueles, porque os resultados podem lhes servir como auxílio na tomada de decisão sobre investir/continuar investindo ou não em determinada empresa do setor, dado o histórico de eficiência de cada uma; e a estas, sobretudo as ineficientes, porque conhecer o seu grau de eficiência em relação ao conjunto analisado pode ser utilizado como um indicador para realinhamento de estratégias de investimentos e aplicação dos capitais dos acionistas, de forma a maximizar o retorno.

Embora este trabalho tenha contemplado exclusivamente a fase de análise e apresentação de resultados, um estudo completo pode considerar a retroalimentação do modelo e a inclusão de outras variáveis, ou associação a outras técnicas capazes de promover a melhoria dos resultados obtidos.

Dessa forma, como sugestões para a realização de possíveis trabalhos futuros, destacam-se: reavaliar as empresas utilizando dados mais recentes, a fim de avaliar se os resultados obtidos neste estudo estão sob a influência de condições específicas, como a proximidade da crise de 2008. Além disso, sugere-se a adoção de outras variáveis que complementem as utilizadas neste estudo. Pode ainda ser aplicado a diversos períodos, possibilitando a verificação da evolução da eficiência das empresas e o resultado dos fatores que contribuíram para o seu crescimento.

\section{Referências}

ANGULO-MEZA, L., BIONDI NETO, L., SOARES de MELLO, J. C. C. B., GOMES, E. G. ISYDS - Integrated System for Decision Support (SIAD - Sistema Integrado de Apoio a Decisão): A Software Package for Data Envelopment Analysis Model. Pesquisa Operacional, Rio de Janeiro, n. 25, p. 493-503, set./dez. 2005. Disponível em: <http://www.scielo.br/pdf/pope/v25n3/27835.pdf>. Acesso em: 15 jun. 2011.

ASSAF NETO, Alexandre. Finanças corporativas e valor. 5. ed. São Paulo, SP: Atlas, 2010 .

ASSAF NETO, Alexandre. Mercado Financeiro. 8. ed. São Paulo: Atlas, 2008.

BM\&FBovespa. Disponível em: <http://www.bmfbovespa.com.br > Acesso em 5 set. 2011.

BRAGA, Roberto. Fundamentos e técnicas de administração financeira. São Paulo: Atlas, 1989.

BUENO, Artur Franco; Os Dividendos Como Estratégia de Investimentos em Ações. Revista Contabilidade \& Finanças - USP. São Paulo, n. 28. p. 39-55, jan.-abr./2002. Disponível em <http://www.eac.fea.usp.br/eac/revista/>. Acesso em: 9 out. 2012. 
CARDIA, Patrícia Gomes; MALQUET, Giseli Oliveira; AMBROZINI, Marcelo Augusto. Abertura de capital das empresas Brasileiras: Onde foram aplicados os recursos na Bolsa? In: SEMEAD, 10, 2007, São Paulo/SP. Anais... São Paulo: SEMEAD, 2007. Disponível em: <http://www.ead.fea.usp.br/semead/10semead/sistema/resultado/trabalhosPDF/298.pdf>. Acesso em: 7 abr. 2011.

CAVALCANTE, Francisco. Gerenciamento baseado no valor. Disponível em: <http://www.v2finance.com.br/artigos3/Gest\%C3\%A3o\%20Baseada\%20em\%20Valor.pdf> Acesso em: 29 maio 2011.

CBIC - Câmara Brasileira da Indústria da Construção. Disponível em: <http://www.cbic.org.br/> Acesso em: $1^{\circ}$ jun. 2011.

CERQUEIRA, Daniel Augusto Camargo; SILVA, José Marcos da; REZENDE, Amaury José; DALMÁCIO, Flávio Zóboli. Impacto da adoção das normas internacionais de contabilidade sobre os preços e os retornos das ações das companhias brasileiras. In: Congresso USP de Iniciação Científica em Contabilidade, 9, 2012. Disponível em: <http://www.congressousp.fipecafi.org/artigos122012/710.pdf>. Acesso em: 9 out. 2012.

CHARNES, A; COOPER, W. W.; RHODES, E. Measuring the efficiency of decision making units. European Journal of Operational Research, 1978. Disponível em: <http://www.vwl.tuwien.ac.at/hanappi/Lehre/MSM2010/Charnes_1978.pdf >. Acesso em 4 abr. 2011.

DEBREU, G. The measurement of Productive Efficiency. Econometrica, n. 3, p. 273-292, 1951.

FARREL, M. The Measurement of Productivity Efficiency. Journal of the Royal Society of Statistical Society, Series A, 120, Part 3, 253-290, 1957.

FERREIRA, Carlos Mauricio de Carvalho; GOMES, Adriano Provezano. Introdução à Análise Envoltória de Dados. Viçosa: Editora UFV, 2009.

FERREIRA, Marco Aurélio Marques; GONÇALVES, Rosiane Maria Lima; BRAGA, Marcelo José. Investigação do desempenho das cooperativas de crédito de Minas Gerais por meio da Análise Envoltória de Dados (DEA). Economia Aplicada, n. 3, Ribeirão Preto, jul./set. 2007. Disponível em: < http://dx.doi.org/10.1590/S1413-80502007000300006> Acesso em: 7 abr. 2011.

GITMAN, Lawrence J. Princípios da administração financeira. 10 ed. São Paulo: Atlas, 2004.

HENDRIKSEN, Eldon S.; BREDA, Michael F. Van. Teoria da contabilidade. São Paulo, SP: Atlas, 1999.

IUDÍCIBUS, Sérgio de. Teoria da Contabilidade. 6. ed. São Paulo: Atlas, 2000.

IUDÍCIBUS, Sérgio de. Análise de balanços. 10. ed. São Paulo: Atlas, 2010.

KASSAI, José Roberto; KASSAI, Sílvia; SANTOS, Ariovaldo dos; ASSAF NETO, Alexandre. Retorno de investimento: a abordagem matemática e contábil do lucro empresarial . 2. ed. São Paulo: Atlas, 2000. 
KRAUTER, Elizabeth. Medidas de Avaliação de Desempenho Financeiro e Criação de Valor: Um Estudo com Empresas Industriais. SEGeT, 3, 2006. Disponível em: <http://www.aedb.br/seget/artigos06/600_artigo\%20medidas.pdf > . Acesso em: 30 maio 2011.

KOOPMANS, T. C. Analysis of Production as an Efficient Combination of Activities. In: Advity Analysis of Production an Allocation, T.C. Koopmans. Ed. Wiley, New York, 1951.

LETA, Fabiana Rodrigues, SOARES DE MELLO, João Carlos C. B., GOMES, Eliane Gonçalves; MEZA, Lidia Angulo. Métodos de melhora de ordenação em DEA aplicados à avaliação estática de tornos mecânicos. Investigação Operacional, 2005, n.2. Disponível em: $<$ http://www.scielo.oces.mctes.pt/scielo.php?pid=S0874-

51612005000200004\&script=sci_arttext $>$. Acesso em: 20 set. 2011.

LOPES, Rodrigo Falco; GALDI, Fernando Caio. Como as variáveis contábeis explicam o retorno das ações: um estudo empírico no mercado brasileiro. In: ANPCONT, 4, 2009. Disponível em: <http://www.furb.br/congressocont/2010/trabalhos/mfc_196.pdf >. Acesso em: 9 out. 2012.

MARTINS, Eliseu; ASSAF Neto, Alexandre. Administração financeira: as finanças das empresas sob condições inflacionárias. São Paulo: Atlas 1996.

MARTINS, Gilberto de Andrade; THEÓPHILO, Carlos Renato. Metologia da investigação científica para as ciências sociais aplicadas. 2. ed. São Paulo: Atlas, 2009.

MATARAZZO, Dante Carmine. Análise financeira de balanços: abordagem gerencial. 6. ed. São Paulo: Atlas, 2010.

NEVES JÚNIOR, Idalberto José das.; MOREIRA, S. A.; MENDES, Frederico. Estudo Exploratório da Fronteira de Eficiência do Indicador de Alavancagem Financeira em Empresas do Setor Telecomunicações a partir da Análise Envoltória de Dados (DEA). Disponível em: < http://www.iapuco.org.ar/Trabajos_2010_Mercosur/A036.pdf>. Acesso em: 10 ago. 2011.

PARETO, Vilfredo. Manual de economia política. São Paulo: Abril cultural, 1984.

PEREIRA DA SILVA, José. Gestão e análise de risco de crédito. São Paulo: Atlas, 1997.

ROSS, Stephen A.; WESTERFIELD, Randolph W.; JAFFE, Jeffrey F. Administração financeira: corporate finance. 2. ed. São Paulo, SP: Atlas, 2002.

ROTH, Guilherme Christian; ALBUQUERQUE, Andrei Aparecido de; SILVA, Denise Mendes da. Uma análise dos impactos causados pela alteração do rating soberano sobre o retorno das ações das dez empresas com maior volume de negociações na BM\&FBOVESPA. Congresso USP de Controladoria e Contabilidade, 12, 2012. Disponível em: <http://www.congressousp.fipecafi.org/artigos122012/98.pdf>. Acesso em: 9 out. 2012.

SANTOS, José Odálio dos; COELHO, Paula Augusta. Análise da relação risco e retorno em carteiras compostas por índices de bolsa de valores de países desenvolvidos e de países emergentes integrantes do bloco econômico BRIC. Revista Contabilidade \& Finanças USP. São Paulo, n. 54. p. 23-37, set./dez. 2010. Disponível em <http://www.eac.fea.usp.br/eac/revista/>. Acesso em: 9 out. 2012.

SOARES DE MELLO, João Carlos C. B.; PIMENTA, Hugo Luís do Nascimento; MACEDO, Marco Aurélio. Decisão da realização de investimentos em tecnologia da informação com 


análise envoltória de dados. Disponível em:

$<$ http://www.producao.uff.br/conteudo/rpep/volume32003/publicacao22003.htm>. Acesso em: 22 set. 2011.

SOARES DE MELLO, João Carlos C. B.; MEZA, Lidia Ângulo; GOMES, Eliane Gonçalves; BIONDI NETO, Luiz. Curso de Análise de Envoltória de Dados. In. Simpósio Brasileiro de Pesquisa Operacional. 37, 2005. Disponível em: <http://www.uff.br/decisao/sbpo2005_curso.pdf>. Acesso em: 22 set. 2011.

SILVA, José Pereira da. Análise financeira das empresas . 7 ed. São Paulo: Atlas, 2005.

STEVENSON, W. J. Estatística aplicada à administração. São Paulo: Harbra, 1986.

VERGARA, S. C. Projetos e relatórios de pesquisa em administração. São Paulo: Atlas, 2000.

YIN, Robert. Case Study Research: Design and Methods. Thousand Oaks, CA: SAGE Publications, 1989.

ZHANG, G.; CHEN. P. How do accounting variables explain stock price movements? Theory and evidence. Journal of Accounting and Economics, n. 43, p. 219-244, 2007. 